\title{
Perception of farmers on importance of insect pollinators in gozamin district of Amhara Region, Ethiopia
}

\begin{abstract}
Pollination and pollinators provide important ecosystem service for human well being. Identifying and managing diversity of pollinators in Ethiopia have significant effect on the conservation and improvement of agricultural yield in terms of quality and quantity on farms. Thus, improvement of yield needs understanding of farmers' perceptions and knowledge on pollination services and the importance of insect pollinators' for agricultural production among other key production and management factors considered. Therefore, the aim of this study was to investigate and document farmers' perception on the importance of insect pollinators, their current status, distributions and farmers' knowledge of the role of insect pollinators in a farmland habitat of the area. Transect sampling, household surveys of 131 house hold heads, focus group discussion, and direct field observation method was used to collect data. The result showed that most farmers $94(77 \%)$ had no knowledge on pollination and the importance of insect pollinators. In addition more than half $76(62.3 \%)$ revealed that they did not know insect pollinators except honeybee. There is also significant difference in their views. Eighty three (68\%) of the respondents could not identify the role of honeybees and other insect pollinators in agricultural seed set with a significant differences. More than half of the respondents $76(62.3 \%)$ were unaware that insect pollinators feed or drink from the plants. Education, knowledge on pollen and/or nectar, and source of information significantly affected knowledge of farmers about pollination and the importance of insect pollinators. However, more than half of the respondents $75(61.5 \%)$ revealed that they have knowledge of the impact of agricultural input (insecticides and herbicides) on insect pollinators' activity. Most farmers $103(84.4 \%)$ thought that insect pollinators population show a declining trend from year to year and $78.7 \%$ perceived that the trend was due to spray of herbicides and insecticides, coupled with drought and deforestation. The study revealed that most of the farmers lack knowledge of pollination and the importance of insect pollinator in agriculture production. Therefore, awareness creation on the importance of pollinators and pollination is urgently needed for the farmers to conserve pollinators.
\end{abstract}

Volume I Issue 5 - 2017

\author{
Misganaw M,' Mengesha $G,{ }^{2}$ Awas $\mathrm{T}^{\prime}$ \\ 'Ethiopian Biodiversity Institute, Ethiopia \\ ${ }^{2}$ Wondo Genet College of Forestry and Natural Resources, \\ Ethiopia
}

\author{
Correspondence: Manaye Misganaw; Ethiopian Biodiversity \\ Institute, PO Box 30726, Addis Ababa, Ethiopia, Tel 0913823986, \\ Email manaye9@gmail.com
}

Received: August 07, 2017 | Published: December 22, 2017

Keywords: ecosystem services, importance of insect pollinators, knowledge of farmers, perception on insect pollinators, pollination, pollinators conservation

\section{Introduction}

Biodiversity and many ecosystem services provide a key instrumental and constitutive factor determining human well-being. Pollination is among a valuable ecosystem services which provides a variety of benefits including food and fiber, plant-derived medicines, ornamentals, aesthetics, genetic diversity, and overall ecosystem resilience. ${ }^{1,2}$ About $2 / 3$ rd of the crop plants that feed the world, and many plant-derived medicines, relies on pollination by insects or animals in order to produce viable seeds. ${ }^{3}$ Pollinators are insects, including honey bees, as well as birds and some mammals, which transfer pollen from one flower to another. They provide ecosystem service that result in the out-crossing and sexual reproduction of many plants. In addition, they benefit human society by increasing food production, food security that in turn improve livelihoods and play a great role in conserving biological diversity in agricultural and natural ecosystems. Reduced agricultural yields and deformed fruit often result from insufficient pollination rather than a deficiency of other agricultural inputs. ${ }^{4}$ Pollinators are considered ecological keystones; because a major threat to pollinators is destruction of habitat and loss of forage. Workplace decisions concerning plant selection, plant removal, and plant health care (particularly pesticides) can make the difference between a healthy, effective pollinator population and one in decline. ${ }^{5}$

Agriculture is the backbone for Ethiopia's economy and long-term food security. It directly supports more than $85 \%$ livelihoods of its population, $46 \%$ of Gross Domestic Product (GDP), and over $80 \%$ of export value. ${ }^{6}$ Currently due to the increase of human populations and land degradation there are too small land plots to support a family. In addition, small farms are less productive than larger ones, resulting in less food security and less food per person. ${ }^{7}$ Thus, strengthening agricultural production without negatively affecting the diversity is very important for Ethiopia. Many farmers in Ethiopia invest in fertilizer, pest control and composting, crop rotation and on other management activities. ${ }^{8,9,10}$ However, they never consider requirements of pollination for their crops productivity.

The Food and Agriculture Organization (FAO) of the United Nations estimated that out of 100 crop species which provide $90 \%$ of food worldwide, 71 are bee-pollinated as cited by.$^{11}$ Currently, there is global loss of pollination services resulted in a $\$ 302$ billion reduction in the value of production across all sectors and regions representing 
a $0.39 \%$ decrease from the 2004 baseline. ${ }^{12}$ This was due to human induced impacts such as habitat destruction, land use change, use of chemicals (pesticides and herbicides), climate change, and invasive species. ${ }^{3,13}$ These also induce a reduction of both the number and species of native insect pollinators of crops and wild plants. ${ }^{14}$ In agroecosystems, abundances and distributions of pollinator species are affecting agricultural yields and other agro-ecosystem functions in many ways. Thus, habitat composition and configuration of a landscape have large impact on local farmers. Service providing organisms, such as pollinators and natural enemies of crop pests, often disperse from natural and semi-natural habitats into farmland, which may increase yields..$^{15}$ Therefore, identifying and managing pollinators' diversity in Ethiopia have significant effect on the conservation and improvement of agricultural yield in terms of quality and quantity on farms. This requires understanding of farmers' perceptions and knowledge on pollination services and the importance of insect pollinators for agricultural production among those key production and management factors that need consideration.

Pollination is one of the many ecosystem services that are provided by agricultural landscape. It may be difficult for farmers to participate in the conservation of ecosystem services without knowing and being convinced of their importance. For farmers to consider managing their lands for conservation of ecosystem services delivered by pollinator which is component of biodiversity it is crucial that they aware the importance of these services for their livelihoods. ${ }^{16}$ According to $^{17}$ flowering plant species $(86 \%)$ require an animal pollinator to reproduce and produce fertile seed. In the absence of pollinators, many native plants couldn't produce seeds and ensure continuity of the plant species to next generation. These seeds and fruits the plants bear are important sources of food for approximately $25 \%$ of birds and many mammal species, including humans. However, as a result of self-incompatibility in many plant species (over 300 species of 70 families), active and functional pollen grains failed to effect fertilization on self pollination lead and lacked seed set. ${ }^{18}$

Though pollinators such as insects are essential for some of the plant species reproductive success and knowing them is vital in Ethiopia, and little is known concerning the significances of insect pollinators. Moreover, perceptions of farmers and awareness about the role of pollinators and its type in agricultural production are largely undocumented. Yet, such information is indispensable for determining the status of pollinators and developing appropriate management plans for the conservation of threatened pollinator species. Thus, the study aims to understand the status, type of insect pollinators and farmers' knowledge of the role of insect pollinators is an important step in information generation for the farming communities and policy-makers. The knowledge gained could be useful to recognize the economic and ecological value of pollinating animals, and potential impacts of loss of pollinators' particularly insect pollinator-related ecosystem services and functions. ${ }^{4}$ Furthermore, the information obtained could be documented for future uses and scaled up to other such places. Therefore, the objective of this study is to investigate and document farmers' perception on the importance of insect pollinators, their current status, distributions and farmers' knowledge of the role of insect pollinators in a farmland habitat of the area.

\section{Materials and methods}

\section{Description of the study site}

The study district (Gozamin) is one of the 166 Districts of
Amhara National Regional State and one of the 20 districts of East Gojjam Zone. It has 25 rural kebeles, and one sub- city center. The district was bordered by Sinan district to the North, Machacle and Debre Eliyas districts to the West, Abay River Gorge to the South and Basoliben and Anedede district to the East. It is placed at about $299 \mathrm{~km}$ from the West of Addis Ababa and $269 \mathrm{~km}$ from Bahir Dar, and located at $10^{\circ} 36^{\prime} 18^{\prime \prime} \mathrm{N}$ and $37^{\circ} 55^{\prime} 02^{\prime \prime} \mathrm{E}$ with an altitudinal range of 1000-3200 meter above sea level (masl.). ${ }^{19}$ The mean annual temperature records of the study area were in between $11.04^{\circ} \mathrm{c}$ and $25^{\circ} \mathrm{c}$, whereas the mean annual rain fall distribution was in between $1448-1888 \mathrm{~mm}$. The district has a population of 153,295 , of which 75,390 are male and 77,905 are female; $2.82 \%$ of the populations are urban dwellers, and $97.18 \%$ live in rural areas. ${ }^{20}$ The population of the district is Amhara ethnic and Amharic is the common language used. Most of the populations (99.97\%) are Orthodox, followed by Muslim $(0.02 \%)$ and the rest are other religion followers. ${ }^{20}$ Sedentary rain feed agriculture is practiced and economy of the people primarily based on mixed cereal agriculture such as Teff, Sorghum, Maize, Barley, Wheat, Pulses, Oil crops, Potato, Vegetables and Fruits. Due to high anthropogenic effect in the study area, most of the original indigenous forest areas have been converted into other land use types, though remnant plants around holy places, inaccessible areas, and left for shade trees still persist some of the remnant common indigenous plant species of the forest include Juneperus procera, Hagenia abyssinica, Podocarpus falcatus, Acacia abysinica, Cordia africana, Ficus sycomorus, Erythrina brucei, Calpurnia aurea, Prunus africana, Carissa spinarum, Rosa abyssinica, Dombeya torrida, Maytenus arbutifolia. ${ }^{19}$

\section{Method of data collection}

Data were collected during 1to30 November, 2015. Both Primary and secondary sources were used to collect the data. The primary data were obtained from Household Surveys (HHS), Focus Group Discussion (FGD), and direct field observations. The secondary data were gathered from secondary sources of published and unpublished literature. For the primary data collection first the study kebeles were selected purposively based on plant and crop variability and relative differences of the altitudinal. Accordingly, three kebeles Enerata, Yebona-Erjena, and Chimit (Figure 1) were selected based on the data from agriculture office. The altitude study sites ranged from 2520 masl. of Enerata, 2320 masl of Yebona Erjena and 1839 masl. of Chimit. The distribution of house heads of each of the kebeles was presented in table 1 below.

From the total 2435 Households (HHS) in three selected kebeles (Table 1) 131 households were sampled for interview using a semi structured questioner. Sample size of the HHS was determined based on $^{21}$ sample size determination equation.

$$
\begin{aligned}
& n o=\frac{Z^{2} P p}{d^{2}} n=\frac{n o}{1+\frac{n o-1}{N}}---(\text { Equation 1: sample determination }) \\
& n o=\frac{(0.1)(0.9)(1.96)^{2}}{(0.05)^{2}}=138.29 n=\frac{138.29}{1+\frac{138.29-1}{2435}}=131
\end{aligned}
$$

Where; no=the desired sample size Cochran's (1977), when population is greater than 10,000

$\mathrm{n}=$ number of sample size when population is less than 10,000 


\section{$\mathrm{Z}=95 \%$ confidence limit i.e. 1.96} $10 \%)$

$\mathrm{P}=0.1$ (proportion of population to be included in the sample i.e.

$$
\text { q=1-P i.e. (0.9) }
$$

$\mathrm{N}=$ total number of population (2435)

$\mathrm{d}=$ Precision or degree of accuracy desired $(0.05)$ precision to precision

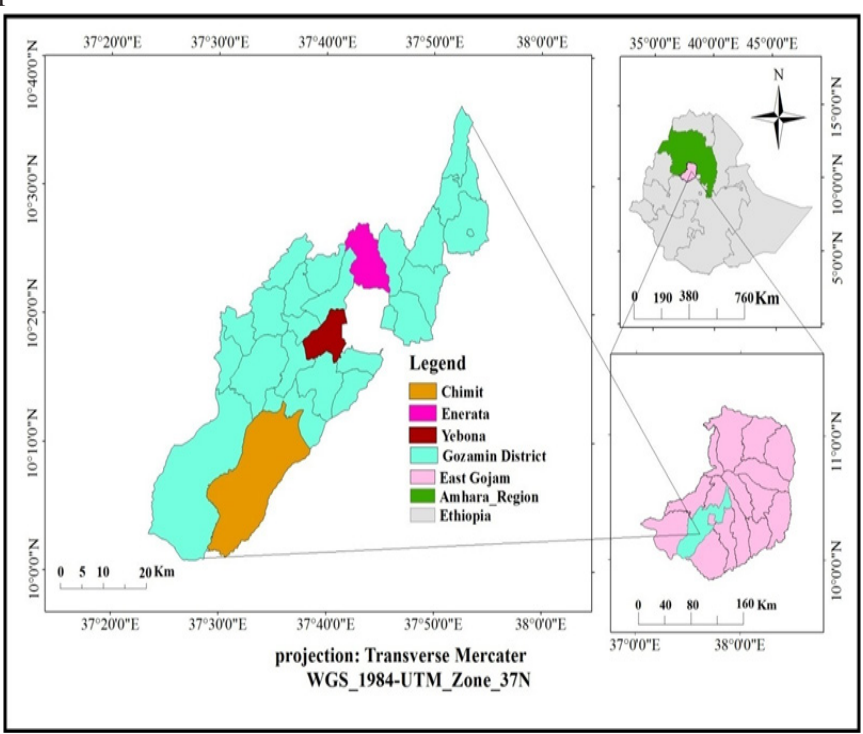

Figure I Map of the study area showing the sample sites.

Table I Household head number of each study site

\begin{tabular}{llll}
\hline $\begin{array}{l}\text { Name of } \\
\text { kebele }\end{array}$ & $\begin{array}{l}\text { Male } \\
\text { household } \\
\text { head }\end{array}$ & $\begin{array}{l}\text { Female } \\
\text { household } \\
\text { head }\end{array}$ & $\begin{array}{l}\text { Total } \\
\text { household } \\
\text { head }\end{array}$ \\
\hline Enerata & 923 & 92 & 1015 \\
$\begin{array}{l}\text { Yebona- } \\
\text { Erjena }\end{array}$ & 628 & 77 & 705 \\
Chimit & 595 & 120 & 715 \\
Total & $\mathbf{2 1 4 6}$ & $\mathbf{2 8 9}$ & $\mathbf{2 4 3 5}$ \\
\hline
\end{tabular}

Out of 131 household 55 from Enerata, 38 from Chimit, and 38 from Yebona-Erjena were interviewed. The number of household selected for interview from each kebeles was sampled in a mathematical relationship (X/2435*131 where; X is total HHS of each study kebele). However, to minimize the risk of biasness during data entry a total of 9 households; 4 from Enerata, 3 from YebonaErjena, and 2 from Chimit was rejected. Missing of important data, error of extension agents during interview (mis-leading), and outlier data were reasons of rejecting the collected data. Thus, a total of 122 household data were encoded using Statistical Package for Social Science (SPSS) version 21.

Focus group discussion (FGD) was also conducted in each kebeles for additional information and to compliment the information gathered. The participants of FGD were selected based on their knowledge and experience on agricultural activities they practiced, and who was in the area for a long time in the kebeles. A total of six (6) group discussions were carried out (two in each kebele). Each FGD has 8 to10 individual participants selected with the help of "kebele extension agents". The interviews and discussion with farmers were conducted in the main local language (Amharic).

\section{Data analysis}

The data were analyzed using Statistical Package for Social Science (SPSS) software version 21. Descriptive statistics such as frequencies, means, percentages, and others were analyzed as far as necessary. Chi-square test and Logistic regression analysis was used to determine factors that influence the knowledge of farmers on pollination and insect pollinators' importance.

\section{Logit model and study hypothesis}

The dependent variable in this study, farmer's knowledge of pollination and insect pollinators' importance, has binary values, i.e., yes or no response. Therefore, the dependent variable can take a value of 1 (yes) with probability of success (the respondent knew pollination and insect pollinators importance), $\mathrm{P}$, or the value 0 (no) with the probability of failure (not having knowledge of pollination and insect pollinators importance), 1-P. The independent variables usually can take any form, since the logistic regression model makes no assumptions about their distribution. ${ }^{22}$

Logistic regression equation is the transformation of $\mathrm{p}$ :

$$
p=\frac{e^{\left(\alpha+\beta_{1} x_{1}+\beta_{2} x_{2}+\ldots \beta_{i} x_{i}\right)}}{1+e^{\left(\alpha+\beta_{1} x_{1}+\beta_{2} x_{2}+\ldots \beta_{i} x_{i}\right)}}
$$

Where $\alpha$ is the constant of the equation and $\beta$ is the coefficient of the predictor variables $x .^{22,23,24}$ An alternative form of the logistic regression equation is:

$$
\operatorname{logit}[\mathrm{P}(\mathrm{x})]=\log \left[\frac{\mathrm{p}(\mathrm{x})}{1-\mathrm{P}(\mathrm{x})}\right]=\alpha+\beta_{1} x_{1}+\beta_{2} x_{2}+\ldots \beta_{i} x_{i}
$$

Since logistic regression calculates the probability of success over the probability of failure, the results of the analysis are in the form of odds ratio. The odd of an event is the probability that the event occurs to the probability that it fails to occur. ${ }^{22}$

\section{Factors selected for logistic regression}

Logistic regression analysis was conducted to predict farmers' knowledge on pollination and insect pollinators' importance. According to ${ }^{22}$ analysis of logistic regression was based on the following selected factors (variable) and description:

a. Gender.......................... . Female 1. male

b. Age........................ Age of the respondent

c. Education........................ Illiterate 2. Read and write $3.1-4^{\text {th }} 4 \cdot 5^{\text {th }}-8^{\text {th }} 5 \cdot 9^{\text {th }}-12^{\text {th }}$

d. Source of informationabout farming(SOI). 0 . From other sources 1 . From extension agent

e. Knowledgeofhoneybees(KHBs). 1. Yes 0 . No

f. The ability to differentiate insect pollinator from crop pest (DPCP)..... 1. Yes 0. No

g. Knowledge of nectar and/or pollen

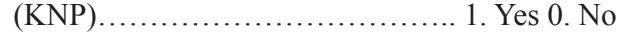




\section{Results and discussion}

More than half of the respondents 54(44\%) were able to read and write with varying illiteracy (Table 2). Average age of respondents interviewed was 44 years with a maximum of 78 and the minimum of 22years old. Most of the respondents 116(95.1\%) were male, which are the main participants of farming activities in the study area. The average land holding of the respondents was 1.9 hectare and the mean

Table 2 Characteristics of the household surveyed (HHS) family size was 6 , which is slightly higher than that of the district average (5person per family). All of the respondents participate in agricultural activities; clearing their farmland, grow crops, and finally harvest products. In the process of growing crops they use insecticide, herbicide and perform management activities. Most respondents $118(96.7 \%)$ visited by extension agents; of these $36.9 \%$ stated that they visited once in a month, $34.4 \%$ once in a week, and the rest $22.1 \%$ once in quarter year.

\begin{tabular}{|c|c|c|c|c|c|c|c|}
\hline \multirow[b]{2}{*}{ Category } & \multicolumn{2}{|c|}{ Gender } & \multicolumn{5}{|c|}{ Education level } \\
\hline & Male & Female & $\begin{array}{l}\text { Read and } \\
\text { write }\end{array}$ & Illiteracy & $I-4^{\text {th }}$ & $5^{\text {th }}-8^{\text {th }}$ & $9^{\text {th }}-12^{\text {th }}$ \\
\hline Responders (No.) & 116 & 6 & 54 & 30 & 9 & 13 & 16 \\
\hline Percentage (\%) & 95.1 & 4.9 & 44.3 & 24.6 & 7.4 & 10.7 & 13.1 \\
\hline Average age & 44.06 & 43.17 & 47.56 & 44.97 & 40.33 & 39.21 & 37.41 \\
\hline
\end{tabular}

\section{Knowledge of insect pollinators and pollination}

The majority of the respondents $94(77 \%)$ thought that they did not know pollination and the importance of insect pollinator $\left(\chi^{2}=71.532\right.$, $1 \mathrm{df}, \mathrm{P}<0.001)$. They $(46.7 \%)$ also considered insect pollinators as a crop pest. Most of the respondents 121(99.2\%) were able to identify honeybees. This implies that farmers are familiar with bees due to the frequent visits of crop and flowers of other plants. However, the result show that a few $35(28.7 \%$ ) of them kept honeybees (Apis mellifera) in the homestead and harvest honey they produce. More than half of the respondents $76(62.3 \%)$ perceived that they did not know other insect pollinators except honeybees $\left(\chi^{2}=57.316,1 \mathrm{df}, \mathrm{P}<0.001\right)$. Some of the respondents $46(37.7 \%)$ listed other insect pollinators but they consider crop pests as insect pollinator. Out of the respondents (46) that considered other insect pollinators $27(22.1 \%)$ of them did not agree on the importance of insect pollinators.

Above half of the respondents $83(68 \%)$ stated that they did not know about the role of honey bees and other insect pollinators in agricultural seed set and 9\% perceived that they have no contribution for the crop rather they visit in order to get feed for themselves. This indicates farmers have no attention for the role they play rather they focused to maximize productivity, thus they do not have knowledge on ecological and economical value of insect pollinators' on seed set. However they perceived that insects destroy their crop, leading to loss of productivity which is a negative implication for pollination and insect pollinators. This implies a need for training and awareness creation to the farmers on the significance of pollinators. When insects visit flowers, not only they collect pollen for themselves but also they transport pollen grains from the stamen to stigma of the same flower and to another flower that ensures reproduction. ${ }^{25}$ This form of pollination can be considered as examples of symbiosis interaction between the species of plants and insect pollinators. ${ }^{25}$ However, a few $(23 \%)$ of the respondents mentioned bees and other insect pollinators have visible role in crossing female and male genital materials of one flower to another thus the crop/plant prepared for seed set.

Another assumed question for knowledge evaluation of pollination and the importance of insect pollinator was distinguishing other bees' species; most of the respondents $105(86 \%)$ did not know other bee species that do not make honey $\left(\chi^{2}=85.952,1 \mathrm{df}, \mathrm{P}<0.001\right)$ and where they nest. However, among those who know, few respondents $(4.9 \%)$ mentioned that they know butterfly and beetles as other bees which do not make honey. This further implies awareness creation on the term pollination and the importance insect pollinator is the basic necessity in the area. This is similar to report by observation ${ }^{26}$ who in Kakamega region (western Kenya) highlights that most farmers were not aware of the importance of pollination for crop production, Other similar study from Uganda shows more than $90 \%$ of small-scale farmers were not aware of the value of pollination service to coffee and to other crops they grow. ${ }^{16}$

Respondents (87\%) thought that insect pollinators were not present throughout the year in the farmland or the surrounding shrub; because, insect pollinators visit a certain crop when bloomed. Otherwise when flowers are absent they can't stay in the farmland rather they shift towards areas where flowering plants are accessed. More than half of the respondents $(54.1 \%)$ were unable to differentiate non pest and pest plant visitors during crops flowering period and while less than half of the farmers $(45.9 \%)$ listed butterfly, beetle, wasp, honey bee, and Meliponinae as non pest visitors and aphid, worm, army worm, termites as a pest. Most of the respondents (94.3\%) know and listed plants visited by honey bees for honey production during flowering season (Figure 2) indicate farmers have understanding about the interaction of honeybees and specific flowering plant that produce honey. Moreover, they are unidirectional in their view about the value obtained from bees' visit that was honey; but, they never consider the indirect service obtained from insect pollinators.

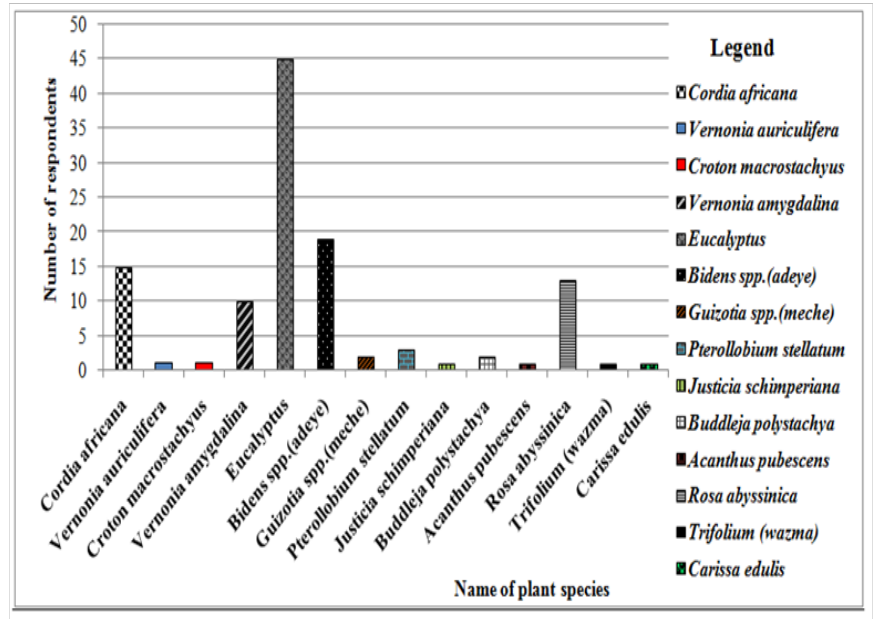

Figure 2 Flowering plant species perceived by farmers for honey production. 
More than half of the respondents $(62.3 \%)$ did not know what insect pollinators feed and drink from flowers $\left(\chi^{2}=57.316,1 \mathrm{df}, \mathrm{P}<0.001\right)$, and $83.6 \%$ of the respondents perceived that the crop or plant did not benefited from bee and other insect visits. Few respondents (8.2\%) perceived that plants can give fruit or seed without flowering. Besides $(23 \%)$ were not sure about the requirement of fertilization for seed and fruit production, while less than half (33.6\%) did not know importance of fertilization for seed setting. These indicate farmers in the area lack knowledge on the importance of pollination; since, they perceive plants gives seeds without flowering and insects could visit any flower in order to get daily feed. However, pollination is a natural ecological process that benefits mankind. Insects pollinate crops, assisting with the process of food production. Pollination can significantly increase the yield of certain crops. In turn, agriculture provides benefits for pollinators, flowering crops are cultivated, land is left open and in the context of cultural landscapes a diversity of ecological niches be provided. ${ }^{25}$

\section{Factors affecting the knowledge of pollination and the importance of insect pollinators}

The logistic regression analysis predicted the knowledge of pollination and the importance of insect pollinators' for 122 households using the predictors listed in the methodology. After complete forward and backward stepwise method of logistic regression analysis of respondents' response on the predictor variables it was shown that three factors were influencing the knowledge of pollination and the importance of insect pollinator (Table 3). Respondents who spent more years in school were more likely to know pollination and the importance of insect pollinator. Similarly, those who got information on farming practice from extension agents were also likely to respond directly to the pollination and the importance of insect pollinator question. Other factors that influenced farmer knowledge of pollination and the importance of insect pollinator were the knowledge of nectar and/or pollen (Table 3). However, gender, age, knowing honey bees, and the ability to differentiate bees from crop pests did not significantly influence knowledge of pollination and the importance of insect pollinator.

Table 3 Factors determining respondent's knowledge on pollination and the importance of insect pollinator

\begin{tabular}{llll}
\hline Variable & Coefficient & Wald & Significance \\
\hline Constant & -4.46 & 0 & 0.997 \\
Education & - & 20.298 & 0 \\
$\begin{array}{l}\text { Source of information about } \\
\text { farming (SOI) }\end{array}$ & -1.737 & 3.56 & 0.059 \\
$\begin{array}{l}\text { Knowledge of pollen and/or } \\
\text { nectar (KNP) }\end{array}$ & 1.993 & 5.505 & 0.019 \\
\hline
\end{tabular}

-2 log likelihood=43.750; Chi square=87.688; Cox \& Snell R2 Square=.5 I3; Nagelkerke's R2 $=.777$

The Model Log Likelihood of education=-51.148; knowledge of pollen and nectar=-24.963; and source of information=-23.992. In addition the change in $-2 \log$ likelihood for education $=58.546$, knowledge on pollen and/or nectar $=6.176$, and source of information $=4.233$ with a significant of the change $.000, .013$, $.040(\mathrm{P}=<.001, \mathrm{P}=<.05$, and $\mathrm{P}=<.05)$ with a degree freedom $4,1,1$ respectively. A test of the full model against a constant only model was statistically significant, indicating that the predictors as a set reliably distinguished between knowledge on pollination and the importance of insect pollinator and those that do not have knowledge on pollination and the importance of insect pollinator $\left(\chi^{2}=87.688, \mathrm{p}<.001\right.$ with $\left.\mathrm{df}=6\right)$. Nagelkerke's $\mathrm{R}^{2}$ of .777 indicated a moderately strong relationship between prediction and grouping the variables. Prediction success overall was $94.3 \%$ which is $96.8 \%$ for no knowledge on pollination and the importance of insect pollinators, and $85.7 \%$ for a positive understanding on pollination and the importance of insect pollinators.

The Wald criterion demonstrated that education, source of information on agricultural practice and the knowledge of pollen and/or nectar made a significant contribution to prediction $(\mathrm{p}=.000$, $\mathrm{P}=.059, \mathrm{P}=.019$ ) respectively (Table 3 ). Gender, age, knowing honey bees, and the ability to differentiate bees from crop pests were not a significant predictor. Similar result was obtained with ${ }^{22}$ except the ability to differentiate bees from crop pests.

\section{Knowledge of insect pollinators' natural history}

Most of the respondents (89.3\%) noted that some bees which get in or out from the ground and Meliponinae were observed repeatedly. Moreover, they practiced how to collect the honey of bees produced from the ground through a technique of tying a tiny rope on the insect which they locally call "molchi"; because, this insect feed the products of Meliponinae. Respondents perceived that the most preferable nesting site of Meliponinae was grazing land, agricultural land, bush land and degraded areas. This shows these places were safer habitats for nesting insect pollinators. More than half of the respondents $(61.5 \%)$ know the impact of agricultural input use on insect pollinators' activity particularly on honeybees $\left(\chi^{2}=56.333,1 \mathrm{df}, \mathrm{P}<0.001\right)$. This indicates farmers will be able to participate actively on future conservation activities if awareness creation and policies are enforced. Besides $(60.7 \%)$ believed that insecticides and herbicides pose high impact on insect pollinators (Figure 3). Respondents (62.3\%) used pesticides and herbicides in order to control agricultural pests and weeds when occurred. Malathion and 2, 4-Dichlorophenoxyacetic acid (usually called 2,4-D) are the most preferable chemicals to control pests and weeds respectively. The time of application of chemicals on the study district was takes place mostly during night and morning (Figure 3).

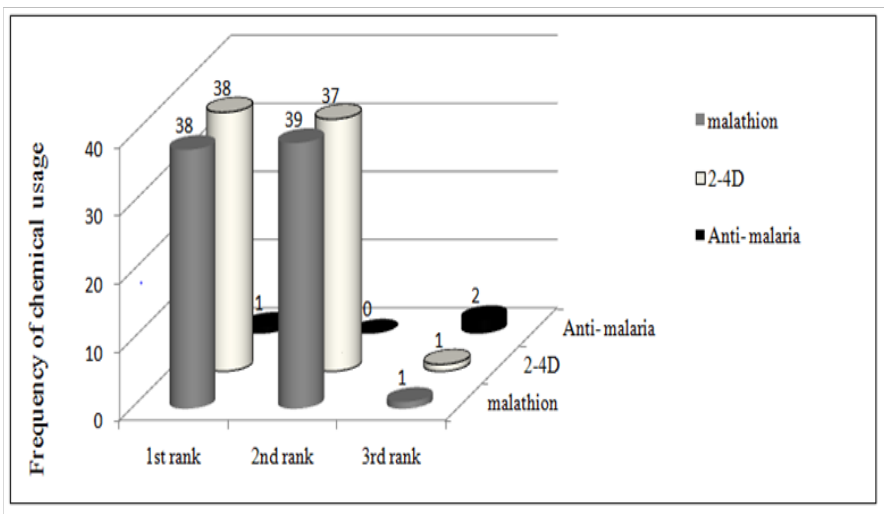

Figure 3 Rank of perceptions' about the impact of agricultural input use on insect pollinators' activity.

Besides respondents adopt knowledge of pest control from locally available materials such as a mixture of livestock urine and ash, clearing the boarder of farmland, frequent ploughing, crop rotation and Juice of Euphorbia abyssinica were the most frequently adopted knowledge's. 
This enables farmers to save money for chemical purchasing and helps researchers to develop new pest controlling mechanism from the knowledge they adopt. An increment of monoculture cropping across the landscape, coupled with other modifications such as weed control programs can cause considerable harm to insect pollinators' populations. Studies documented that reductions in wild pollinator populations impacts both their capacity to pollinate wild plants on which our ecosystems depend and their potential to assist with crop pollination. ${ }^{27,28}$

Almost all of the respondents (97.5\%) practiced fencing around the homestead or farming. This indicates farmers were adopting agrobiodiversity system by reducing deforestation pressure on additional land. Besides it allows farmers to cope with a limited farming area and resources. Thus, they can get additional income from the activities practiced, and it provides habitat for pollinator species in the wild.

\section{Attitude of farmers' towards the conservation of insect pollinators}

More than half of the respondents $(60.7 \%)$ perceived that they do not want to increase insect pollinator diversity in their farmland. Farmers raised different perception about why they were not interested to increase pollinators; for instance, insect feeding reduces productivity $(18 \%)$, they didn't know the importance of insect pollinators $(18 \%), 19.7 \%$ perceived no use for the crop, and $1.6 \%$ believed that pollinators attract crop pests. However, less than half $(39.3 \%)$ were interested on insect pollinators' increment on its farmland; because insect pollinators facilitate pollination activities, honey production, and crop productivity.

Most of the farmers $(84.4 \%)$ perceived that insect pollinators' populations were declining from year to year, and $9.8 \%$ perceived that insect pollinators' diversity was increasing. The rest $(4.9 \%)$ perceived insect pollinators population size remained the same. Most of the respondents $(78.7 \%)$ stated that the reason for decrease in insect pollinators was due to spray of herbicides and insecticides, coupled with drought and deforestation (72.1\%); and few respondents (7.4\%) lack of awareness, $(4.1 \%)$ water shortage and $(3.3 \%)$ shrinkage of grazing land due to uncontrolled ploughing. Others stated $(2.5 \%)$ land degradation, $(2.5 \%)$ migration of pollinators, and $(2.5 \%)$ deforestation due to investment. In addition few respondents $(1.6 \%)$ stated predation by insectivore birds, increment of honeybee enemies, disease of plant and pollinator, and chemical use for controlling malaria also perceived as reasons for declining insect pollinator diversity.

\section{Focus group discussion (FGD)}

Discussion held with local people shows that most of the farmers' $48(92.3 \%)$ did not know the meaning of pollination and the importance of insect pollinators. Moreover, FGD did not aware the importance of insect pollinators except honey bee. Most of the discussants $51(98.1 \%)$ thought that yield from agricultural particularly from cereal crops are increasing. This is due to the focus of government to produce sufficient food using improved seed, fertilizers, and other important agricultural inputs. However, according to the discussants oil crop productivity decreased relative to the past years was due to land shortage and disease problem. Thus, productivity as compared to cereals was low. Most of the discussants 39(75\%) perceived that the presence of honeybees benefit beekeeper not the community. They also perceived bees and other insect pollinators visit flowers to get their own feed not for the benefit of crops grown. All discussants $52(100 \%)$ reveled that local peoples affect the conservation of insect pollinators in an attempt to use insecticides and herbicides. Most of them $39(75 \%)$ perceived that conserving honeybees increase profit to the keeper, but conserving other insect pollinator would never add any benefit for the community rather considered as a crop pests especially when they are in excess.

\section{Conclusion and recommendations}

The study revealed that a few farmers know but most of them did not know pollination and the importance of insect pollinators' for agricultural productivity and maintenance of ecosystem integrity. However, the present study showed other insect pollinators considered as pests of crops by most farmers. This implies farmers have negative attitude towards the other pollinators and this requires urgent need for pollinators' conservation in its study area. The study also revealed that insecticides, herbicides and other chemicals are negatively impacting insect pollinators' diversity. In addition, this study further revealed that perception and knowledge of pollination and the importance of insect pollinator could be improved by educating local farmers. Therefore, awareness creation on the importance of insect pollinators and pollination is urgently needed to farmers of the study area to conserve insect pollinators. Moreover, government need to strengthen the extension department and giving continual training to the farmers on pollination and pollinators' importance, its role, impacts of deforestation and chemical use, and why conserve insects. Continuing curriculum based education to strength future farmer's capacity on pollination and the importance of insect pollinators. Also further research is needed to identify other crop pest from pollinators and create awareness to farmers.

\section{Acknowledgements}

I am sincerely grateful to Ethiopian Biodiversity Institute, for the financial support and leave of absence for the entire study period. My thanks also went to the staff of Gozamin District Agricultural Office, especially Mr. Esuyawukal Tirunehe and development agents of the study sites. The cooperation and patience of local people that participated in group discussion and interview was also likely appreciated.

\section{Conflict of interest}

I declared no conflict of interest between the authors.

\section{References}

1. Millennium Ecosystem Assessment. Ecosystems and Human Well-being: Biodiversity Synthesis. World Resources Institute, Washington, USA; 2005.

2. Nabhan GP, Buchmann SL. Pollination services: biodiversity's direct link to world food stability. In: Daily GC, editor. Nature's Services: Societal Dependence on Natural Ecosystems. 1997. p. 133-150.

3. Food and Agriculture Organization. Tools for Conservation and use of pollination service, Initial Survey of Good Pollination Practices, Global Action on Pollination Services For Sustainable Agriculture, Rome, Italy; 2008 .

4. African Pollinator Initiative. Pollinators and pollination: A resource book for policy and practice. 2006. p. 1-52.

5. Peterson W, Johnstone R, Ellsworth D, et al. Pollinators and Rights-of-Way. 2015. p. 36-39.

6. Alemu D. Seed system potential in Ethiopia: Constraints and opportunities for enhancing the seed sector. Ethiopian Institute of Agricultural Research, Ethiopia; 2010. p. 1. 
7. Ministry of Finance and Economic Development. Population Growth and the National Vision. Population Affairs Directorate, Government of Ethiopia, Ethiopia; 2010. p. 33.

8. Amera T, Abate A. An Assessment of the Pesticide Use, Practice and Hazards in the Ethiopian Rift Valley. Pesticide action network, UK; 2008. p. 11-32.

9. Bizuayehu Alemu. Practices, Challenges and Prospects of Agricultural Land Management in Machakel Woreda, East Gojjam Zone, Ethiopia. Department of Natural Resources and Environmental Management, Addis Ababa University, Ethiopia, 2014. p. 40.

10. Tola M. Factors Affecting Sustainable Land Use Management: The Case of Warra Jarso Woreda, Oromiya, Ethiopia. Department of Geography and Environmental Studies, Addis Ababa University, Ethiopia; 2015. p. 29.

11. United Nations Environment Programme. UNEP Emerging Issues: Global Honey Bee Colony Disorder and Other Threats to Insect Pollinators, Nairobi, Kenya; 2010. p. 1-12.

12. Bauer DM, Wing IS. The Macroeconomic Cost of Catastrophic Pollinator Declines. Department of Geography and Environment, Boston University, USA; 2011. p.13.

13. Kearns CA, Inouye DW, Waser NM. Endangered Mutualism: The Conservation of Plant-pollinator Interaction. Annu Rev Ecol. 1998;29:83-112.

14. Vanbergen AJ, The Insect Pollinators Initiative. Threats to an ecosystem service: pressures on pollinators. Frontiers in Ecology and the Environment. 2013;11(5):251-259.

15. Bianchi F, Booij CJH, Tscharntke T. Sustainable pest regulation in agricultural landscapes: a review on landscape composition, biodiversity and natural pest control. Proceedings of the Royal Society B-Biological Sciences. 2006;273(1595):1715-1727.

16. Munyuli T. Farmers' perceptions of pollinators' importance in coffee production in Uganda. Agricultural Sciences. 2011;2(3):318-333.
17. Ollerton J, Winfree R, Tarrant S. How many flowering plants are pollinated by animals? Oikos. 2011;120(3):321-326.

18. Patil HS, Duhoon SS. Self Incompatibility, Male Sterility and Pollination Mechanism in Niger \{Guizotia abyssinica (L.F.) CASS.\}. A review. Indian journals. 2006;27(2):113-121.

19. Reta H, Asfaw Z, Kelbessa E. Contribution of Traditional Farmers for Medicinal Plant Conservation on the Farming Site in Gozamin District, Amhara Region, Ethiopia. International Journal of Life Sciences. 2015;4(1):24-35.

20. Gozamin District Finance, Economic Development office. The second five year Growth and transformation plan. Integrated Budget Planning and development case team (unpublished). Ethiopia; 2015. p. 4-5.

21. Cochran W. Sampling techniques, 3rd edn. Wiley, New York; 1977.

22. Kasina JM. Bee Pollinators and Economic Importance of Pollination in Crop Production: Case of Kakamega, Western Kenya. INRES. 2007. p. $1-152$.

23. Eckel S. Interpreting Logistic Regression Models. 2008. p. 1-53.

24. Field A. Discovering Statistics Using SPSS, 3rd edn. Sage Publications Ltd., London; 2009. p. 264-313.

25. EISA. Pollinators and Agriculture Agricultural Productivity and Pollinator Protection. European Initiative for Sustainable Development in Agriculture, European Crop Protection. 2013. p. 1-48.

26. Kasina M, Kraemer M, Martius C, et al. Farmers' knowledge of bees and their natural history in Kakamega district, Kenya. Journal of Apicultural Research and Bee World. 2009;48(2):126-133.

27. Klein AM, Vaissiere BE, Cane JH, et al. Importance of pollinators in changing landscapes for world crops. Proceedings of the Royal Society. 2007;274(1608):303-313.

28. Spivak M, Mader E, Vaughan M, et al. The plight of the bees. Environmental Science and Technology. 2011;45(1):34-38. 